\title{
¿CUATRO O SIETE IMPERIOS UNIVERSALES?
}

\author{
ERIK JiMÉNEZ MiLla \\ Docente de LA FACULTAD DE TEOLOGIA - UPEU
}

\section{Introducción}

Al leer Daniel se entiende que, para él, los imperios mundiales serían tan sólo cuatro. Según el capítulo 2, el quinto imperio sería el "Reino de Dios" simbolizado por la piedra cortada no con mano. Daniel ratifica que en este mundo no existirá un reino que intente gobernar en forma parecida a los primeros cuatro grandes imperios; esto sería imposible. El profeta declara que no se mezclarán nunca más. Quienes intentaron hacerlo han tenido que reconocer su atrevimiento después del trago amargo que significó su anunciada derrota. Los diez dedos de los pies, son el símbolo de un mundo totalmente dividido, como contexto para el establecimiento del reino que nunca tendrá fin.

El objetivo de este artículo es mostrar bíblicamente la existencia de siete imperios, aunque la visión central o la que establece el todo de la visión futura del mundo, habla de la existencia de sólo cuatro imperios universales; Apocalipsis 17 presenta a siete. El porqué lo hace y cómo, se entiende esta ampliación, de cuatro a siete imperios, se responderá al final de esta breve investigación.

Se comienza con la hipótesis de que los imperios deben ser contados desde el contexto de Daniel. Apocalipsis es entonces la continuación de Daniel, principio historicista de interpretación. Además, para identificar los siete imperios es necesario conocer el tiempo de la expresión "uno es" registrado en Apocalipsis 17:10. La esencia de éstos destaca que la historia es una línea continua que está bajo el control de Dios y que se mueve siempre a una gloriosa consumación dirigida por su intervención divina, cuando su reino de justicia sea establecido por la eternidad. ${ }^{1}$

La metodología a seguir está basada sobre un análisis teológico

'Kenneth Strand, “Apocaliptic Prophecy and the Church”, Ministry (Octubre 1993): 20-3. 
de las interconexiones de las profecías de Apocalipsis 13 y 17 con las de Daniel 2 y 7. Para ello hay que encontrar el tiempo de la descripción del ángel. Después de identificar los cinco imperios se contrastará con el postulado de que no pueden existir más de cuatro imperios.

\section{Tiempo de la expresión "uno es"}

Encontrar el momento exacto cuando el ángel expresa esta frase, dará la verdadera identidad de los reinos, entonces recién se puede conectar en forma sucesiva los imperios.

Una primera posición defiende que los acontecimientos que Juan refiere en tiempo presente, tienen su interpretación literal y tienen que ser ubicados en el tiempo del mismo apóstol.

Allí toma lógica la explicación de muchos autores ${ }^{2}$ que buscan cinco imperios antes de Juan. Egipto y Asiria llegan a añadirse a la lista de Daniel. Siendo el Imperio Romano la sexta cabeza, "uno es", y la entidad que aún no ha llegado es una manifestación de un futuro desde la perspectiva de Juan. Entonces, la expresión "uno es" es literal y significa el tiempo de Juan. Los imperios y las expresiones quedarían así:

Diagrama 1: Interpretación de los reinos en el tiempo de Juan - "Uno es".

\begin{tabular}{|c|c|c|c|c|c|c|}
\hline Egipto & Asiria & Babilonia & Medo-Persia & Grecia & $\begin{array}{c}\text { Roma } \\
\text { Imperial }\end{array}$ & $\begin{array}{c}\text { Roma } \\
\text { Papal }\end{array}$ \\
\hline $\begin{array}{c}\text { El poder } \\
\text { que ha } \\
\text { caído }\end{array}$ & $\begin{array}{c}\text { El poder } \\
\text { que ha } \\
\text { caído }\end{array}$ & $\begin{array}{c}\text { El poder } \\
\text { que ha } \\
\text { caído }\end{array}$ & $\begin{array}{c}\text { El poder } \\
\text { que ha caído }\end{array}$ & $\begin{array}{c}\text { El poder } \\
\text { que } \\
\text { ha caído }\end{array}$ & $\begin{array}{c}\text { El poder } \\
\text { que es }\end{array}$ & $\begin{array}{c}\text { El poder que } \\
\text { aún no ha } \\
\text { venido }\end{array}$ \\
\hline lra. cabeza & 2da. cabeza & 3ra. cabeza & 4ta. cabeza & 5ta. cabeza & 6ta. cabeza & 7ma. cabeza \\
\hline
\end{tabular}

Parece convincente el argumento, habría que considerar la estructura del Apocalipsis. Si bien es cierto que el inicio histórico en las

${ }^{2}$ Como Jon Paulien, Armageddon at the Door (Hagerstown, MD: Autumn House Publishing, 2008), 204-23; Ranko Stefanovic, Revelation of Jesus Christ Revelation of Jesus Christ: Commentary on the Book of Revelation (Berrien Springs, MI: Andrews University Press, 2002), 512 . 
profecías de las siete iglesias, los siete sellos y las siete trompetas tienen su fuente en el periodo del apóstol, no significa que todas las otras profecías tienen el mismo inicio.

Se conoce, por la estructura del libro, que Apocalipsis 17 pertenece a la sección escatológica, ubicada entre la sexta y séptima plaga (Ap 16), y tiene relación con el juicio de la mujer ramera (Ap 17:1-5). La división de las dos secciones mayores del libro, una histórica y otra escatológica, permiten entender que el capítulo 17 está en la parte escatológica, donde los acontecimientos son desarrollados en un aspecto espiritual; donde la batalla se extiende a lo celestial y no sólo a lo terrenal y a lo histórico.

Otro aspecto que puede considerarse para estipular el tiempo de la expresión "uno es", es la división de todo el libro en los dos momentos de la labor de Jesús en el Santuario Celestial: en el lugar santo y en el lugar Santísimo. En Apocalipsis 1 Jesús es visto paseando entre los siete candeleros, dice el v. 12: "Y me volví para ver de quién era la voz que hablaba conmigo. Y al volverme, vi siete candeleros de oro" (Ap 1:12). Estos textos indican que Jesús posiblemente se encontraba en el lugar santo.

Apocalipsis 17 está ubicado en el esquema del lugar santísimo, al estar en el contexto de la declaración del capítulo 11:19: "El templo de Dios que está en el cielo fue abierto; y el arca de su pacto se veía en su templo". Las profecías de Daniel tienen la explicación para este dilema, donde Daniel 8: 14 determina el inicio del ministerio sumo sacerdotal de Jesús en el santuario celestial, al final de las 2300 tardes y mañanas.

Juan es transportado en la visión al momento escatológico en que se vivían las escenas, por lo que el ángel declara: "cinco han caído", "uno es" (Ap 17:10). Esta posición lleva a esclarecer el tiempo exacto de todas las expresiones que da el vidente.

El momento cuando debemos ubicar la profecía de Apocalipsis 17, en relación con la Bestia, no es partiendo en la época de Juan sino de los conceptos y escenas que Juan ya ha visto y teniendo en cuenta lo ya dicho. Muchos autores confunden al autor de Apocalipsis y su época como la línea temporal límite con la que debemos entender el ahora, des- 
pués o el antes. El autor es un mero instrumento arrebatado en la visión. ${ }^{3}$ LaRondelle acepta esta postura, ${ }^{4}$ y junto con la interpretación que da Maxwell, quien ve la visión de la bestia escarlata "desde el punto de vista del tiempo del fin en lugar de ubicarse en los días de San Juan". El tiempo del fin, según ellos, comenzó en 1798, al final de los 1260 años. Se puede entender mejor observando el siguiente diagrama:

Diagrama 2: Los Siete Reinos a la luz del tiempo del fin (escatología) - “uno es”.

\begin{tabular}{|c|c|c|c|c|c|}
\hline \multicolumn{4}{|c|}{5 HAN CAÍDO } & UNA ES & $\begin{array}{l}\text { EL OTRO AÚN NO } \\
\text { HA VENIDO: Y CUANDO } \\
\text { VENGA, ES NECESARIO } \\
\text { QUE PERMANEZCA UN } \\
\text { POCO TIEMPO }\end{array}$ \\
\hline ler REINO & 2do REINO & 3er REINO & 4to REINO 5to REINO & REINO ACTUAL & REINO FUTURO \\
\hline \multicolumn{4}{|c|}{ ANTES DE 1844} & DESPUÉS DE 1844 & FINAL DE LA HISTORIA \\
\hline \multicolumn{4}{|c|}{ LUGAR SANTO } & \multicolumn{2}{|c|}{ LUGAR SANTÍSIMO } \\
\hline Ira CABEZZA & 2da CABEZA & 3ra CABEZA & 4ta CABEZA 5ta CABEZA & Gta CABEZA & $7 \mathrm{ma}$ CABEZA \\
\hline \multicolumn{4}{|c|}{ TIEMPO HISTÓRICO } & \multicolumn{2}{|c|}{ TIEMPO ESCATOLÓGICO } \\
\hline
\end{tabular}

Se comienza a entender que los cinco primeros imperios van en un momento distinto que los últimos dos. Pero eso no es todo, el quinto imperio parece ser fundamental para entender a los últimos dos.

\section{Los cuatro "imperios" y su contraste con el quinto "reino"}

Según la profecía matriz (Dn 2), el establecimiento del quinto reino sería un reino eterno. Es así como Daniel 2, muestra el todo, expone sólo cuatro imperios universales, mostrando al final de la historia al imperio de los imperios. A través de un esquema completo determina 1995), 2: 453-4.

${ }^{3}$ Antolín Diestre Gil, El sentido de la historia y la palabra profética (Barcelona: CLÍE,

${ }^{4}$ Hans LaRondelle, Las profecías del fin, trad. David Gullón (Buenos Aires: Asociación Casa Editora Sudamericana, 1999), 416-9.

${ }^{5}$ Mervyn C. Maxwell, Apocalipsis: Sus revelaciones (Buenos Aires: Asociación Casa Editora Sudamericana, 1991), 475-6. 
que el quinto imperio es la piedra cortada no con mano humana, puesto que cae en la tierra y establece el reino cristiano tan esperado, en donde Cristo estará reinando con poder y gran autoridad. Es el reino en donde "la raíz y linaje de David", sale vencedor y es un poderoso guerrero. La profecía establece que no habrá otro reino universal, en la forma en que los primeros cuatro gobernaron el mundo. Entonces el quinto sería otro tipo de reino, el reino espiritual de Jesús.

Diagrama 3: El quinto imperio: El reino eterno de Dios.

\begin{tabular}{|c|c|c|c|c|c|}
\hline Babilonia & $\begin{array}{c}\text { Medo- } \\
\text { Persia }\end{array}$ & Grecia & Roma & $\begin{array}{c}\text { Mundo } \\
\text { Dividido }\end{array}$ & $\begin{array}{c}\text { Reino Eterno } \\
\text { de Dios }\end{array}$ \\
\hline Cabeza & Brazo Pecho & $\begin{array}{c}\text { Vientre y } \\
\text { muslos }\end{array}$ & Piernas & Pies & Piedra \\
\hline Oro & Plata & Bronce & Hierro & $\begin{array}{c}\text { Hierro y } \\
\text { barro } \\
\text { cocido }\end{array}$ & $\begin{array}{c}\text { Desmenuza } \\
\text { todos los } \\
\text { metales- } \\
\text { Monte llena } \\
\text { toda la tierra }\end{array}$ \\
\hline ler REINO & 2do REINO & 3er REINO & 4to REINO & $\begin{array}{c}\text { No más } \\
\text { reinoso } \\
\text { imperios } \\
\text { mundiales }\end{array}$ & $\begin{array}{c}\text { 5to REINO } \\
\text { JESÚS } \\
\text { REINANDO }\end{array}$ \\
\hline
\end{tabular}

Frente a este panorama, por qué siete cabezas o reinos? ¿Cuál es la relación con el esquema histórico de los reinos descritos en las profecías de Apocalipsis? Para llegar a la respuesta, es necesario mostrar si Apocalipsis 17 tiene conexión con las profecías de Daniel.

El capítulo 13 de Apocalipsis se conecta con facilidad, allí la bestia de siete cabezas y diez cuernos tiene las características de las bestias de Daniel 7: el león, el oso y el leopardo. ¿Será esta bestia de Apocalipsis 13 la misma del 17?

La conexión entre Apocalipsis 13 y 17, está dada con la bestia y el desarrollo de sus tiempos. Juan Millanao presenta un resumen de este asunto ${ }^{6}$, en donde el panorama de estos dos capítulos puede quedar sugerido así:

${ }^{6}$ Pablo Millanao, “Apocalipsis 17: 9-11: Una visión de las siete cabezas bestiales y la mujer ramera", Advenimiento 3. 1 (2006): 72-90. 
Diagrama 4: Conexión de Apocalipsis 13 con Apocalipsis 17.

\begin{tabular}{|c|c|c|}
\hline Profecía & Cap. 13 (v.1,2) & Cap. 17 (v.8,11) \\
\hline $\begin{array}{c}\text { Pasado } \\
\text { Durante los 1260 años }\end{array}$ & $\begin{array}{c}\text { Memorias daniélicas } \\
\text { (Leopardo, Oso, León) }\end{array}$ & "era" \\
\hline $\begin{array}{c}\text { Presente } \\
\text { Después de los 1260 } \\
\text { años }\end{array}$ & Una cabeza herida & "ya no es" \\
\hline Futuro & $\begin{array}{c}\text { Revive y el mundo se } \\
\text { maravilla }\end{array}$ & $\begin{array}{c}\text { "está por subir del abismo"; } \\
\text { "Octavo" "Todos se } \\
\text { maravillan viendo a la } \\
\text { bestia" }\end{array}$ \\
\hline Tiempo & $\begin{array}{c}\text { Siete cabezas; diez } \\
\text { cuernos con diademas }\end{array}$ & $\begin{array}{c}\text { Siete cabezas; } \\
\text { cuernos sin diademas }\end{array}$ \\
\hline
\end{tabular}

Como se puede observar, las acciones de la bestia de Apocalipsis 13 y las de Apocalipsis 17 son las mismas. Simultáneamente se relacionan las expresiones "era", "ya no es" y "será", a la imagen de la bestia y sus acciones descritas en Apocalipsis 13. ${ }^{7}$ Entonces, este capítulo conecta a la profecía de la bestia de siete cabezas y diez cuernos con Daniel. Para ilustrar mejor esta relación, se ha estructurado este esquema. Ver el siguiente diagrama.

Diagrama 5: El paralelismo de Daniel 2, 7 y 8 con Apocalipsis 13 y 17.

\begin{tabular}{|c|c|c|c|c|}
\hline Daniel 2 & Daniel 7 & Daniel 8 & Apocalipsis 13 & Apocalipsis 17 \\
\hline Babilonia & Babilonia & - & León & \multirow{5}{*}{$\begin{array}{l}\text { CINCO } \\
\text { HAN } \\
\text { CAÍDO }\end{array}$} \\
\hline Medopersia & Medopersia & Medopersia & Oso & \\
\hline Grecia & Grecia & Grecia & Leopardo & \\
\hline Roma & Roma & Roma Pagana & & \\
\hline $\begin{array}{l}\text { LOS DEDOS } \\
\text { DE LOS PIES } \\
\text { (HIERRO) }\end{array}$ & Roma Papal & Roma Papal & $\begin{array}{c}\text { Breve alusión a } \\
\text { su origen bestial } \\
\text { La Bestia que } \\
\text { sube del } \\
\text { mar }\end{array}$ & \\
\hline
\end{tabular}

${ }^{7}$ Esta relación también es presentada por Antolín Diestre Gil, El sentido de la historia y la palabra profética, LaRondelle, Las profecías del fin; entre otros. 
Como se nota, dentro del contexto daniélico, Apocalipsis 13 elimina aquellos imperios que no están en conexión con las profecías de Daniel. Es así como el conteo comienza desde Babilonia, primer imperio dentro del contexto profético.

Para clarificar la identidad de los siete imperios, Apocalipsis 17: 10 dice: "cinco han caído, uno es y el otro aún no ha venido; y cuando venga, es necesario que permanezca un poco de tiempo". La expresión "cinco han caído", como se ve en el diagrama, hace que se retroceda hasta los imperios daniélicos, entonces la identidad de estos reinos quedaría así:

Diagrama 6: Los cinco reinos.

\begin{tabular}{|c|c|c|c|c|}
\hline \multicolumn{5}{|c|}{ CINCO HAN CAÍDO } \\
\hline Babilonia & Medo Persia & Grecia & Roma Imperial & Roma Papal \\
\hline 605-538 a.C & 538-331 a.C & 331-168 a.C & 168 a.C.-476 d.C. & 476-1798 d.C. \\
\hline
\end{tabular}

\section{La quinta cabeza}

La conexión que da Daniel 7 es importante porque la quinta bestia es trascendental en la comprensión de las otras dos. Cuando Daniel 7 presenta los imperios mundiales recapitula a los cuatro imperios de Daniel 2. Respetando lo establecido en ese capítulo, presenta un reino distinto, que no pretendería instituir un imperio mundial político, sino establecer el quinto imperio en nombre de Jesús. A quien pretenda esta función se lo llama el anticristo.

Daniel lo llama simplemente el cuerno pequeño. El surgimiento de este cuerno no es un misterio, ya que se describe su accionar en Daniel 7. Los detalles de este surgimiento servirán para entender también su osadía blasfémica. Para ello hay que recapitular con la Biblia su historia profética.

La cuarta bestia terrible, espantosa y en gran manera fuerte que tenía enormes dientes de hierro, devoraba, desmenuzaba y hollaba los restos con sus pies. Era diferente de todas las bestias que le antecedieron y tenía diez cuernos (Dn 7:7). Esta cuarta bestia es Roma Paga- 
na, extremadamente fuerte y perseguidora. Pero tuvo su fin, los diez cuernos representaban el cómo este imperio cesaría, y tendría que ser conquistado por 10 tribus bárbaras.

La declaración bíblica es básica: "mientras yo contemplaba los cuernos, he aquí, otro cuerno, uno pequeño, surgió entre ellos, y tres de los primeros cuernos fueron arrancados delante de él; y he aquí, este cuerno tenía ojos como los ojos de un hombre, y una boca que hablaba con mucha arrogancia" (Dn 7: 8). Este quinto imperio aparece como el "octavo" reino, ya que derribó a tres de los diez cuernos, quedando siete reyes, por lo que la suma ya no es diez sino ocho cuernos. Este octavo cuerno es diferente a todos los demás.

"Mientras yo miraba, este cuerno hacía guerra contra los santos y prevalecía sobre ellos" (Dn 7:21). "Y él proferirá palabras contra el Altísimo y afligirá a los santos del Altísimo, e intentará cambiar los tiempos y la ley; y le serán entregados en sus manos por un tiempo, por tiempos y por medio tiempo" (Dn 7: 25). Es la misma bestia que describe Apocalipsis 13, llega a perseguir por 1260 años a los fieles de Dios, sólo aquí parece con otro símbolo para referirse a este periodo, "tiempo, tiempos y medio tiempo". Un tiempo equivale a un año; tiempos a dos años; y medio tiempo a medio año. Cada año equivale a 360 días o años proféticos, lo que hacen 1260 años.

Queda en incertidumbre, lo relacionado con el misterio del "cuerno pequeño" en relación al octavo reino, cuando se estudie la expresión "el octavo". ${ }^{8}$ Este quinto imperio estaba establecido bajo este símbolo, ser distinto a los otros cuatro.

Si se evalúa la forma de reinado de los primeros cuatro imperios, como se ve en la historia real de cada uno de ellos, se concluye que se trataba de imperios poderosos. Naciones que conquistaron el mundo por su poderío bélico y al gran ejército que lograban formar. Tenían el poder político, económico y religioso.

El quinto imperio es distinto, no conquistaría nada con poderío bélico. La profecía señalaba claramente que todo el mundo quedaría dividido, y no habría un reino mundial político después de Roma Imperial representada por las piernas de la estatua. Sin embargo, Daniel

${ }^{8}$ En un artículo posterior se expondrá el significado del "octavo" en la Biblia. 
mismo propone que habría uno que, desafiando todas las profecías, intentaría establecer el "quinto reino", el reino de Jesús en esta tierra. Este poder tomaría el liderazgo de una manera distinta a los cuatro imperios mundiales. Dice el texto "y los diez cuernos de este reino son diez reyes que se levantarán, y otro se levantará después de ellos; él será diferente de los anteriores y subyugará a tres reyes" (Dn 7:24). La palabra "diferente" implica la estrategia distinta que usaría para establecer su reinado.

Este reino "diferente" tendría una característica, no era parte de los diez que conquistaron a Roma Pagana, se agenciaría de artimañas distintas para lograr establecer el quinto reino en nombre de Cristo, derribando a tres y estableciéndose como el octavo. Esta apreciación puede entenderse en el siguiente diagrama.

Diagrama 7: Los cinco reinos y los 10 reyes.



Según las descripciones dadas a la primera bestia del Apocalipsis 13 , la quinta cabeza de la secuencia de siete hace que los intérpretes ${ }^{9}$ la sitúen descubriendo quién es la que tuvo ese gobierno por más de mil 
años. Es entre los años 538 y 1798, la historia tiene el deber de identificar al reino que, con hegemonía total, trajo persecución y muerte a los santos de esos tiempos.

Apocalipsis 13 presenta primero a una bestia con su poder o hegemonía intenta establecer un reino eterno como lo establece Daniel cuando describe al verdadero "reino de Dios". Como no es el auténtico reino, recibe una herida de muerte; sin embargo, se recupera. Son los tres momentos de acción que tiene esta bestia. ${ }^{10}$ Interpretando bajo el simbolismo del número "tres", resulta evidente que se trata de un poder que actúa tratando de imitar a Dios. Es un reino que toma atributos divinos, ya que el énfasis del tres determina este estado blasfémico. ${ }^{11}$ Es el anticristo. Se puede explicar de una manera clara con un esquema lógico.

Diagrama 8: "Era, ya no es y será” - Los tres momentos de la bestia.

\begin{tabular}{|c|c|c|}
\hline ERA & YANO ES & SERÁ \\
\hline 5ta CABEZA & 6ta CABEZA & 7ma CABEZA \\
\hline Ap 13:1-10 & Ap 13:11-17 & Ap 13:14-18 \\
\hline $\begin{array}{c}\text { Durante los 1260 años. } \\
\text { Tiempo, tiempos y medio } \\
\text { tiempo 42 meses. }\end{array}$ & Después de los 1260 años & Al final de los tiempos \\
\hline $\begin{array}{c}\text { Satanás le da poder y } \\
\text { gran autoridad }\end{array}$ & $\begin{array}{c}\text { Una cabeza con herida de } \\
\text { muerte }\end{array}$ & $\begin{array}{c}\text { Pero su herida mortal } \\
\text { fue sanada }\end{array}$ \\
\hline
\end{tabular}

Lo interesante de estos tres momentos de la bestia, es que cuando recibe la herida de muerte, la bestia que asume el poder hace cesar la persecución, y crea un ambiente distinto al determinado en los 1260 años. Esa bestia que en el tiempo profético se distingue con la expresión "una

${ }^{10 "}$ "El ángel interpretador describe las tres etapas sucesivas de la bestia, era, ya no es $y$ será, en forma repetida (dos en el vers. 8 y una en el vers. 11). De esta manera el ángel enfatiza tres veces que la visión de Juan pertenece al período cuando la bestia "no es", es decir, cuando no está reinando como perseguidora de los santos, mientras la bestia está "para subir (mélei anabáinein) del abismo" (Apoc. 17:8). Esta descripción determina el punto de vista del tiempo de la visión de Apocalipsis 17 , cuando la bestia "no es", de decir cuando ha recibido su "herida mortal". LaRondelle, Las profecias del fin, 421.

${ }^{11}$ Para un mayor estudio, ver Erik Jiménez, "La bestia de Apocalipsis 17 y la aparición de Satanás en la tierra", Revista Estrategias 6.1 (2009): 18-20. 
es", comienza a regir como Cordero (Ap 13: 11), por lo que no hay más absolutismo religioso, sino una libertad plena (EE.UU). En ese contexto, a la bestia herida no le queda más que cambiar su estrategia, entonces se entiende la expresión, "y la tierra entera se maravilló de la bestia" (Ap 13: $3 c)$. En esa etapa, ella esconde sus pretensiones de poder, reino y gran autoridad. En el diagrama aparece en relación a la expresión, "YA NO ES". ${ }^{2}$ La lógica de la profecía determina que el retorno de su poder, reino y gran autoridad, se hace notorio cuando vuelve a perseguir y querer imponer al mundo sus argumentos engañosos y blasfemos. Es la etapa de poder y reino y gran autoridad y sin esto la herida está curada en forma parcial, pero no definitiva. Entonces el día cuando la bestia recupere el poder, el reino y la gran autoridad, Apocalipsis 13 concuerda en su lógica que es la sexta bestia que le da su autoridad, reino y poder, y hace que todo el mundo vaya tras la bestia, ahora que su herida está curada. Se puede complementar la ilustración anterior con los detalles del siguiente diagrama.

Diagrama 9: "Era, ya no es, y será" en el contexto de "persecución"

\begin{tabular}{|c|c|c|}
\hline 5ta CABEZA & 6ta CABEZA & 7ma CABEZA \\
\hline ERA & YA NO ES & SERÁ \\
\hline Durante los 1260 años. & Después de los 1260 años & Al final de los tiempos \\
\hline Persecución a los Santos & $\begin{array}{c}\text { No hay persecución visible/ } \\
\text { Maravilla a toda la tierra }\end{array}$ & Persecución a los Santos \\
\hline
\end{tabular}

\section{Conclusión}

Es así como el quinto reino se convierte en la meta de Satanás. Todo el horizonte profético se completa en la visión del quinto imperio, y es donde Satanás intenta dirigir su accionar, al intentar establecer este quinto imperio, en nombre de Jesús. Este quinto reino sería un reino religioso, toma la autoridad de Dios y gobierna el mundo. Es así como

${ }^{12}$ Para una mejor comprensión de la influencia de Estados Unidos en la historia, ver en este número, Iván Balabarca, "El crecimiento de los Estados Unidos de Norteamérica y su relación con apocalipsis 13 ". 
Daniel 7 muestra la aparición de un reino, llamado el cuerno pequeño, el cual tendría la osadía de querer establecer el "reino eterno". Prefigurando el poder y la autoridad se atrevería a decir que ha venido a reinar con "vara de hierro". Pretendió establecer el cumplimiento de las profecías; sin embargo, no contaba con Apocalipsis. El símbolo de la piedra sería tomado en virtud de un hombre, el pontífice, que haga las veces del representante de Cristo en esta tierra.

Lógicamente todos los reinos que han surgido han tenido tal pretensión, ser eternos, nunca dejar de existir; sin embargo, este quinto reino sería distinto y actuaría en tres etapas. La sexta cabeza también tendría los mismos fundamentos e inicios, como un poder religioso. Finalmente, el séptimo tendría que ser la reaparición del "octavo". Bajo este esquema se proponen los siete imperios de la siguiente manera.

Diagrama 10: Identidad de los siete reinos.

\begin{tabular}{|c|c|c|c|c|c|c|}
\hline \multicolumn{7}{|c|}{ LA BESTIA COBIERNA A TRAVÉS DE LAS 7 CABEZAS } \\
\hline \multicolumn{5}{|c|}{ CINCO HAN CAÍDO } & UNO ES & NO HA VENIDO \\
\hline \multicolumn{4}{|c|}{ Contexto Histórico } & & & \\
\hline 1ER & 2DO & 3ER & 4TO & $5 \mathrm{TO}$ & 6TO & $7 \mathrm{MO}$ \\
\hline $\begin{array}{l}\text { B } \\
\text { A } \\
\text { B } \\
\text { I } \\
\text { L } \\
O \\
N \\
1 \\
\text { A }\end{array}$ & $\begin{array}{l}M \\
E \\
D \\
O \\
\\
P \\
E \\
R \\
S \\
I \\
A\end{array}$ & $\begin{array}{l}G \\
R \\
E \\
C \\
\text { I } \\
A\end{array}$ & $\begin{array}{c}\mathrm{R} \\
\mathrm{O} \\
\mathrm{M} \\
\mathrm{A} \\
\mathrm{I} \\
\mathrm{M} \\
\mathrm{P} \\
\mathrm{E} \\
\mathrm{R} \\
\mathrm{I} \\
\mathrm{A} \\
\mathrm{L}\end{array}$ & $\begin{array}{l}\text { ROMA } \\
\text { PAPAL } \\
\text { Cuerno } \\
\text { Pequeño }\end{array}$ & $\begin{array}{c}\text { EE.UU. } \\
\text { Roma Papal } \\
\text { herida de } \\
\text { muerte }\end{array}$ & $\begin{array}{c}\text { TRIPLE UNIÓN } \\
\text { Roma Papal Revivida } \\
\text { toma el liderazgo } \\
\text { mundial }\end{array}$ \\
\hline \multicolumn{4}{|c|}{ DANIEL 2 Y 7} & ERA & Y NO ES & SERÁ \\
\hline \multicolumn{4}{|c|}{$\begin{array}{l}\text { GOBIERNOS POLÍTICOS } \\
\text { MUNDIALES }\end{array}$} & \multicolumn{3}{|c|}{ GOBIERNO DEL ANTICRISTO EN 3 FASES } \\
\hline
\end{tabular}

